\title{
BMJ Open Awareness on menstrual hygiene management in Bangladesh and the possibilities of media interventions: using a nationwide cross- sectional survey
}

\author{
Awan Afiaz (D) , ${ }^{1}$ Raaj Kishore Biswas (D) ${ }^{2}$
}

To cite: Afiaz A, Biswas RK. Awareness on menstrual hygiene management in Bangladesh and the possibilities of media interventions: using a nationwide crosssectional survey. BMJ Open 2021;11:e042134. doi:10.1136/ bmjopen-2020-042134

- Prepublication history and additional online supplemental material for this paper are available online. To view these files, please visit the journal online (http://dx.doi.org/10. 1136/bmjopen-2020-042134)

Received 27 June 2020 Revised 27 January 2021 Accepted 09 April 2021

Check for updates

(c) Author(s) (or their employer(s)) 2021. Re-use permitted under CC BY-NC. No commercial re-use. See rights and permissions. Published by BMJ.

${ }^{1}$ Institute of Statistical Research and Training, University of Dhaka, Dhaka, Bangladesh

${ }^{2}$ Transport and Road Safety (TARS) Research Centre, School of Aviation, University of New South Wales, Sydney, New South Wales, Australia

Correspondence to

Awan Afiaz; aafiaz@isrt.ac.bd

\section{ABSTRACT}

Objectives Menstrual hygiene management (MHM) has become a growing public health concern in many lowincome and middle-income nations for its association with several health risks. This study observed types of menstrual absorbents used among women in Bangladesh and analysed the associated sociodemographic factors with the hypothesis that mass media can increase awareness regarding MHM. The study includes recommendations for possible intervention strategies designed to address this lack of awareness.

Design and participants The analysis used the data from the nationally representative Bangladesh Multiple Indicator Cluster Survey 2019 that employed a two-stage, stratified cluster sampling approach, with a study sample of 54242 women aged between 15 and 49 years. A generalised linear model was fitted to the data adjusting for survey weights and cluster/strata variations along with bivariate analyses and spatial mapping.

Results Only a quarter of women (24.3\%) used modern absorbents for MHM with most resorting to unhygienic traditional practices. Spatial distribution showed that the use of modern absorbent of MHM was limited to the major cities. The women who had mobile phones and regular access to the media were nearly $43 \%$ (adjusted OR (AOR) 1.43 with $95 \% \mathrm{Cl} 1.33$ to 1.54) and 47\% (AOR 1.47 with $95 \% \mathrm{Cl} 1.35$ to 1.60 ) more likely to use the modern absorbents of MHM, respectively. Furthermore, educated women living in urban solvent households with educated house heads were also found to use modern absorbents of MHM.

Conclusions There appeared to be scope for interventions through a combined national effort to raise awareness using multifaceted media channels regarding MHM among women in order to meet the Sustainable Development Goals 3.7 and 6.2 of addressing women's healthcare and hygiene needs.

\section{INTRODUCTION}

Menstrual hygiene management (MHM) is the process of dealing with menstruation by collecting or absorbing menstrual blood using different materials safely and with dignity. Menstruation and MHM are important health
Strengths and limitations of this study

- The study covers all 64 districts of Bangladesh with a sample size of 54242 using a nationally representative sample.

- The study addressed the urgent need regarding the lack of awareness about menstrual hygiene management (MHM) and the associated health risks for women resulting from using unhygienic absorbent materials.

- Spatial mapping was conducted to assess the district-wise distribution of menstrual absorbent materials used by the women

- This study was limited to only one aspect of MHM, the type of menstrual absorbent materials used.

- The extent to which the pieces of cloths and rags used by women were cleaned and reused could not be ascertained from the available data.

issues for females in their reproductive years. ${ }^{1}$ Most women and girls often face adversities regarding menstrual hygiene due to a lack of access to accurate information and sufficient knowledge. $^{2}$

The unfettered access to safe and dignified menstruation is a necessity for women of reproductive age. The WHO and the UNICEF Joint Monitoring Programme for drinking water, sanitation and hygiene consider the use of clean menstrual management material to absorb or collect menstrual blood as an integral part of the MHM. ${ }^{1}$ There are two methods of menstrual blood collection under MHM. The safer modern method, such as using disposable sanitary pads and the traditional method, such as using reused old cloths or rags. ${ }^{3}$ Broader systemic factors such as women's health, well-being, gender equality, education, equity, empowerment and rights are associated with menstruation, ${ }^{1}$ which make MHM an important component 
in the public health system. Although the concept of MHM is quite broad according to the definition provided by UNICEF, the present analysis will focus its discussion on the materials used for MHM by Bangladeshi women.

The use of unhygienic materials during the menstruation is likely to have adverse effects on women's health. Khanna $e t$ at ${ }^{4}$ found that girls in India who used old cloths or other unsafe materials during menstruation were three times at risk of contracting reproductive tract infections compared with safer materials users, such as sanitary napkins and new cloths. The reuse of cloth has been associated with abnormal vaginal discharge, skin irritations, and urogenital infections. ${ }^{1}$ Furthermore, women using reusable absorbent material were more than twice as likely to be diagnosed with at least one or more urogenital infections (bacterial vaginosis (BV) or urinary tract infection) than women who were using disposable sanitary pads. ${ }^{5}$ BV due to poor menstrual hygiene could increase pregnancy risk such as delivery of low birthweight (LBW) infants, preterm delivery of LBW infants, and clinical chorioamnionitis. ${ }^{5-7}$

Studies focusing on underdeveloped and developing countries' menstrual hygiene found that most women and girls regularly failed to maintain a healthy menstrual hygiene practice. ${ }^{8-10}$ Limited resources, economic hardship, traditional norms and lack of education force women to seek alternative unhygienic methods and materials ${ }^{11}$. Even in cases where females had sufficient knowledge regarding MHM, this did not translate to the practice of good menstrual hygiene due to adverse sociocultural views and stigmatisation of menstruation, ${ }^{13}$ which demanded the identification of the most vulnerable group of women.

There is a considerable literature gap on the menstrual hygiene practices in Bangladesh. Few studies that had been conducted were mostly on adolescent females. ${ }^{14-16}$ Similar to many low-income and middle-income countries (LMICs), discussion on menstruation and menstrual hygiene practices is socially stigmatised. ${ }^{17}$ Misconceptions regarding menstruation, insufficient facilities at school and family restrictions were found to be risk factors for school absenteeism among adolescent girls in Bangladesh. ${ }^{14}$ A study on adolescent girls in Chittagong, the second-largest city of Bangladesh, observed that girls were not made aware of menstruation until after menarche. ${ }^{16}$ The use of old pieces of cloth as absorbent materials during the menstruation was common in both rural and urban areas. ${ }^{16}$

A study on the slums of Dhaka, the capital of Bangladesh, found that about $95 \%$ of women and $90 \%$ of adolescent girls reused rags during menstruation without adequate cleaning, which resulted in scabies in the vaginal area, urinal infections, and complications during the pregnancy. ${ }^{17}$ Furthermore, the use of poor-quality reused cloths which are usually dyed with toxic materials is likely to make women susceptible to various urogenital diseases. ${ }^{15}$ Unsurprisingly, only $57 \%$ of adolescent girls felt confident dealing with menstrual bleeding while at home, whereas only $7 \%$ of girls felt confident dealing with menstruation while in school. ${ }^{18}$ However, no nationally representative study was conducted to assess countrywide MHM practices in Bangladesh.

The objective of this study is to assess the current practice of the modern method of menstrual absorbents among women of reproductive age through district-wise distribution in Bangladesh and identify the impact of media in this practice. The spatial distribution of modern menstrual absorbent was conducted to estimate the use of modern methods across the country. For evaluating the safer practices of MHM, this study assessed the impact of access to any general form of media, such as newspapers, televisions, radio and the internet as well as the use of mobile phones. The article proposed an intervention plan based on an awareness campaign that would be suitable for addressing the issue of MHM in LMICs, specifically in Bangladesh. This will provide a feasible pathway to help attain the Sustainable Development Goal (SDG) 3.7 (universal access to sexual and reproductive healthcare services) and SDG 6.2 (access to adequate and equitable sanitation and hygiene) proposed by the United Nations. ${ }^{19}$

\section{Theoretical framework}

Healthcare access is the mechanism that identifies healthcare needs and enables one to seek relevant services and resources in order to use or obtain these services or products as necessary. ${ }^{20}$ In the present study of MHM, this concept of access to health services or products is fundamental to the apprehension of the distribution of menstrual materials. Penchansky and Thomas ${ }^{21}$ formally conceptualised the theory of healthcare access, where they discussed five dimensions that optimised access, namely accessibility, availability, acceptability, affordability and accommodation (or adequacy). ${ }^{22}$ Later awareness was proposed as the sixth dimension of access by Saurman ${ }^{23}$ as it considers effective communication and knowledge about the service to the users.

Few variables in the context of the present study could address the four dimensions namely accessibility, acceptability, affordability and awareness (figure 1). However, due to a lack of relevant information in the data, the dimensions of availability and adequacy (accommodation) could not be addressed on the access of the modern methods of MHM for women in Bangladesh. Also, some important actors who contribute to the accessibility and health promotion such as scholars, health activists, students, non-governmental organisations (NGOs), media, government and corporations ${ }^{24}$ are missing in the data used in this study and thus not part of the theoretical framework.

Part of the objective of this study is to discuss the possibility of intervention strategies. Interventions can be classified into two broad categories, hardware and software interventions. ${ }^{25}$ Hardware interventions address the issues regarding materials and water, sanitation and hygiene ${ }^{26}$ facilities, while the software interventions address the 


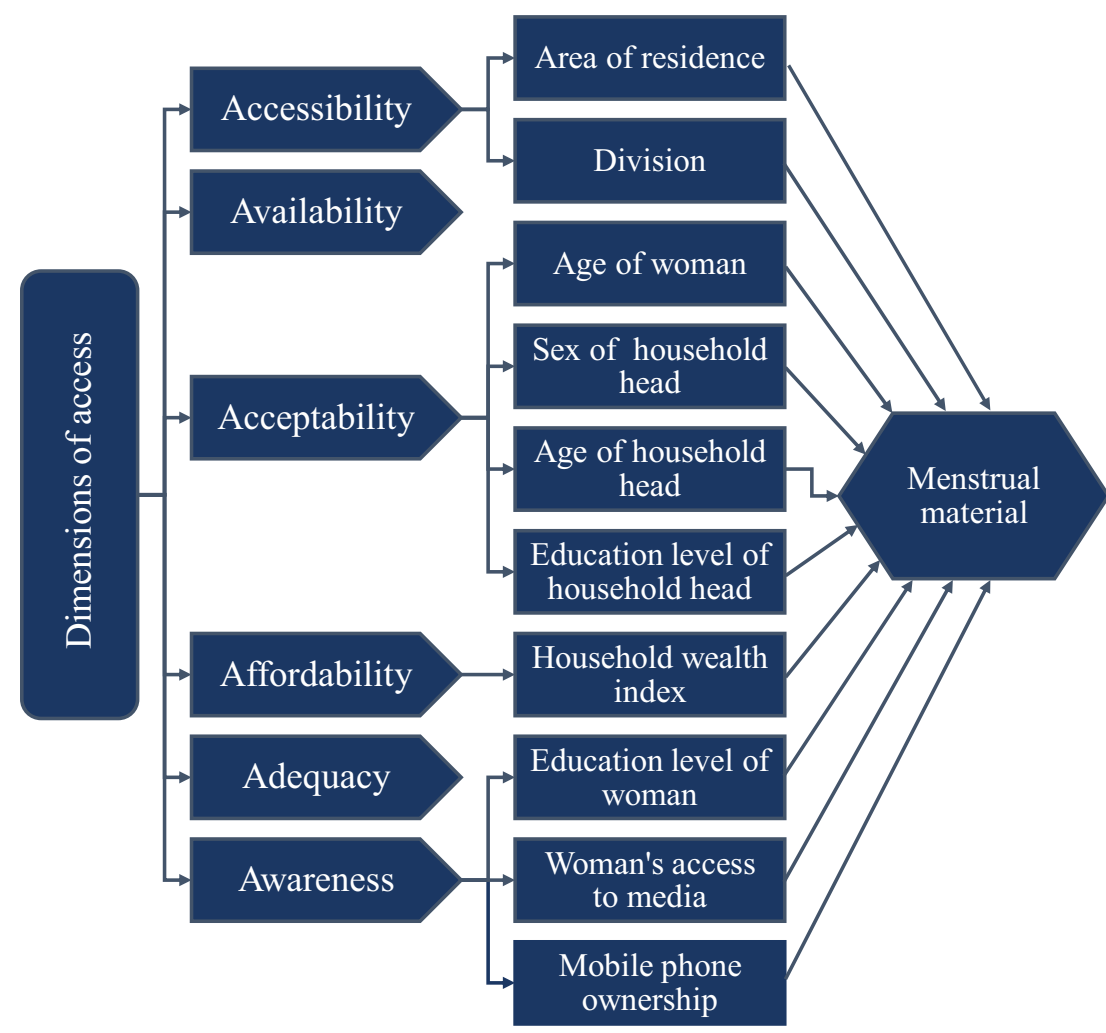

Health accessibility theory

Context of current study

Figure 1 Theory of healthcare access in the context of women's access to modern menstrual material.

deficits in knowledge and management regarding menstruation by providing the necessary education. ${ }^{25}$ This study would focus on software interventions.

\section{MATERIALS AND METHODS \\ Data overview}

The current study used the nationally representative Bangladesh Multiple Indicator Cluster Survey (MICS) $2019 .{ }^{27}$ The survey employed a two-stage, stratified cluster sampling approach. The enumeration areas (EAs) were considered the primary sampling units. In the first stage of sampling, a total of 3220 EAs were selected from the sampling strata (64 districts) using a probability proportional to size method. In the second stage, a sample of 20 households was selected from each cluster (EA) using random systematic selection procedures. ${ }^{28}$ This resulted in a final sample size of 64400 households, consisting of approximately 1000 households from each stratum.

The current study considered women, aged 15-49, who menstruated within the last 12 months prior to the survey. Several sociodemographic factors related to the women and their household characteristics were included as well. The study used the complete records analysis approach and after the removal of cases with missing values, the final sample size was 54242 .

\section{Independent variables}

The study considered the variables related to women's frequent access to media, namely, reading newspapers weekly (does not read, reads), listening to radio weekly (does not listen, listens), watching television weekly (does not watch, watches), using internet weekly (does not use, uses) and owning a mobile phone (no, yes). These four variables (newspaper, radio, television and internet) were recoded to a binary variable named 'women's access to media' (with access, without access), where women who responded affirmatively to using at least one of these forms of media at least once a week or everyday were considered in the 'with access' category. This variable corresponds to the dimension of awareness belonging to the healthcare access theory. The Household Wealth Index was precalculated in MICS 2019 data using principal component analysis based on ownership of household assets. ${ }^{27}$

The sociodemographic variables pertaining to women and their household characteristics were explored for association with the use of menstrual material. These variables included age of women (continuous); educational level of women and household head (none or preprimary, primary completed, secondary, higher secondary or above); Household's Wealth Index quintile (poorest, poorer, middle, richer, richest); area of residence (urban, rural); administrative division (Dhaka, Chattogram, Khulna, Sylhet, Barishal, Rajshahi, Mymensingh, 
Rangpur); age (continuous) and sex (male, female) of the household head.

\section{Outcome variable}

The type of material used during the last menstruation (which occurred within the last 12 months) was the outcome variable for the study. Two types of materials were considered, the modern sanitary napkins and the traditional cloths. ${ }^{3}$ Women who used other types of materials (cotton pads, tissues, others) constituted less than two percent in the MICS 2019 and were excluded from the study. Thus, the model was fitted to the outcome variable 'type of material' with two categories: traditional $(n=41052)$ and modern $(n=13190)$.

\section{Ethical clearance}

This study was based on an analysis of secondary survey data from UNICEF, where all the personal identifiable information of participants had been removed. Informed consent was taken from participants before participating in the survey by the national statistical office, Bangladesh Bureau of Statistics and UNICEF.

\section{Patient and public involvement}

No patients and public were involved in any way in this study.

\section{Statistical analysis}

In order to estimate the primary associations of sociodemographic factors by the type of menstrual material used, bivariate analyses ${ }^{29}$ including $\chi^{2}$ tests were conducted to identify the relevant variables, which would be included in the model. The binary outcome variable was then fitted to these significant variables using a generalised linear model (GLM) to estimate the adjusted ORs (AOR) and their subsequent significance. ${ }^{30}$ The cluster and strata-wise variations and survey weights were adjusted to generalise the findings from the model. The analyses were performed in $\mathrm{R}$ (V.3.6.0). The bivariate analyses were conducted using the 'gmodels' package (V.2.18.1) and the binary logistic regression model (GLM) was fitted using the 'survey' package (V.3.37).

To assess the spatial pattern of modern menstrual absorbent of MHM in Bangladesh, district-wise mapping of modern material use was conducted. Data from the Natural Earth project ${ }^{31}$ was used through the R-package 'maps' (V.3.1.0). ${ }^{32}$

The current study analyses employed a level of significance threshold of 0.005 , following the recommendation of Benjamin $e t a l^{33}$ to ensure reproducibility in scientific research in cases of new discoveries. Therefore, the associations from the model were considered significant if $p$ values were less than 0.005 in the GLM.

\section{RESULTS}

\section{Bivariate analyses}

The district-wise spatial mapping on the distribution of the proportion of modern menstrual absorbent material usage among women of reproductive age in figure 2 reveals that traditional absorbents of MHM are common in most districts of Bangladesh. In only a handful of districts, mostly adjacent to the capital city Dhaka, more than one-third of females used sanitary napkins out of the 64 districts. The highest percentage belonged to the Dhaka district, where still half of the women and girls of reproductive ages used pieces of old reused cloth to absorb menstrual blood, with nearly $93 \%$ of them reusing these materials.

The descriptive analysis in table 1 shows that, throughout the country, approximately one out of every four females used modern materials (sanitary napkins) during their previous menstrual periods within the past 1 year. Nearly $80 \%$ of the women lived in the rural areas and a vast majority $(79.8 \%)$ of them used traditional material of menstrual hygiene. The Dhaka division had the highest proportion of women using modern materials at $31.2 \%$ and Mymensingh having the lowest at $13.4 \%$. About two-thirds of women who had education beyond the secondary level used sanitary napkins compared with $6.4 \%$ of women with primary level education. Women belonging to richer households were found more prone to using modern materials than women from poorer households. Just above $10 \%$ of households had female heads and a higher proportion of modern material usage was observed in those families compared with families with male heads. Nearly $55 \%$ of women from households with highly educated house heads used modern materials for their MHM.

Television was the most popular form of media with approximately two-thirds of women accessed it at least once weekly (table 1 ). Nearly $10 \%$ women had used the internet within the last 3 months prior to the survey and about $30 \%$ of women said they owned a mobile phone. A higher percentage of women with access to media, the internet or mobile phones were reported to use modern materials during menstruation. Women who had used any one of these media (newspaper, radio, television and/or internet) reported a higher percentage $(30.7 \%)$ of using modern materials during menstruation than women who did not $(10.5 \%)$.

\section{Generalised linear model}

All sociodemographic variables considered in the GLM were significantly associated with the type of absorbent material used during menstruation (table 1). The estimates revealed that older women were less likely (AOR 0.92 with $95 \%$ CI 0.91 to 0.92 ) to use modern methods as the odds of using modern absorbent materials decreased by $8 \%$ for each year increase in age. For women living in urban areas, $33 \%$ higher odds was associated with women living in the urban areas than women residing in the rural areas (AOR 1.33 with 95\% CI: 1.21, 1.46)). Women who completed primary (AOR 1.34) or secondary (AOR 3.19) or higher (AOR 8.58) levels of education were more likely to use modern sanitary napkins compared with women who had either pre-primary or no education. Aside 


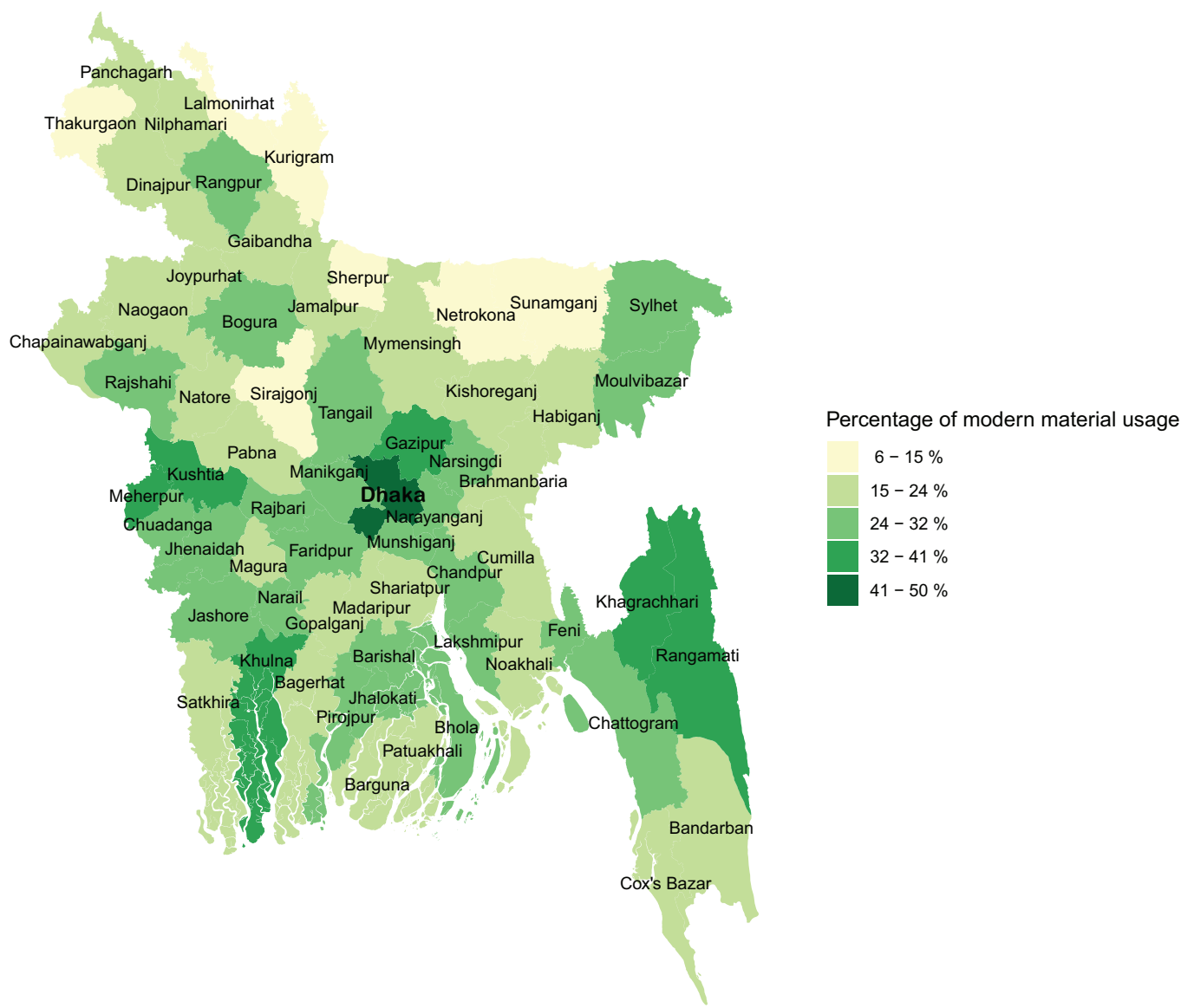

Figure 2 A district-wise mapping on the distribution of modern menstrual material (sanitary napkins) in Bangladesh.

from Barishal and Khulna, lower odds of using modern menstrual absorbent was associated with women across all other divisions compared with the Dhaka division. The lowest OR was found in the Mymensingh division where the odds of women using modern materials was nearly half as much as Dhaka (AOR 0.52 with $95 \%$ CI 0.43 to $0.63)$.

From the perspective of household characteristics, women who belonged to the middle (AOR 1.79), richer (AOR 2.77) and richest (AOR 6.92) categories of wealth index had higher odds of using modern absorbent materials during menstruation. Having older household heads was also associated with slightly higher odds of using modern materials (AOR 1.01 with $95 \%$ CI 1.01 to 1.02 ) as well as having a female household head (AOR 1.27 with $95 \%$ CI 1.15 to 1.40 ). The higher educational level of the household heads significantly increased the chances of using modern menstrual materials compared to household heads with no or preprimary education.

Ownership of mobile phones by women was associated with $43 \%$ higher odds (AOR 1.43 with 95\% CI 1.33 to 1.54) of using modern absorbent materials in contrast to women who did not own a mobile phone (table 2).
Most importantly, the awareness indicator media access, which referred to women who had at least weekly or more frequent access to any form of media (newspaper, radio, television and/or internet) had nearly 1.5 times higher odds (AOR 1.47 with 95\% CI 1.35 to 1.60 ) of using modern sanitary napkins compared with women without such access.

Lastly, the presence of multicollinearity in the model was assessed through the squared adjusted generalised variance inflation factor (GVIF) scores. Since the threshold value for the squared adjusted GVIFs for categorical variables is equivalent to the typical VIF threshold for continuous variables and all of such scores from the models were well below 5 , this suggested that there was no multicollinearity in the model. ${ }^{3435}$ The detailed results are added in online supplemental table 1.

\section{DISCUSSION}

The current study assessed the role of awareness among women in their reproductive age on their menstrual health and associated hygiene management materials. Women with greater access to media and with higher 
Table 1 The distribution of the usage of menstrual materials (traditional and modern) by sociodemographic variables (categorical and continuous) among women aged 15-49 years from the MICS 2019

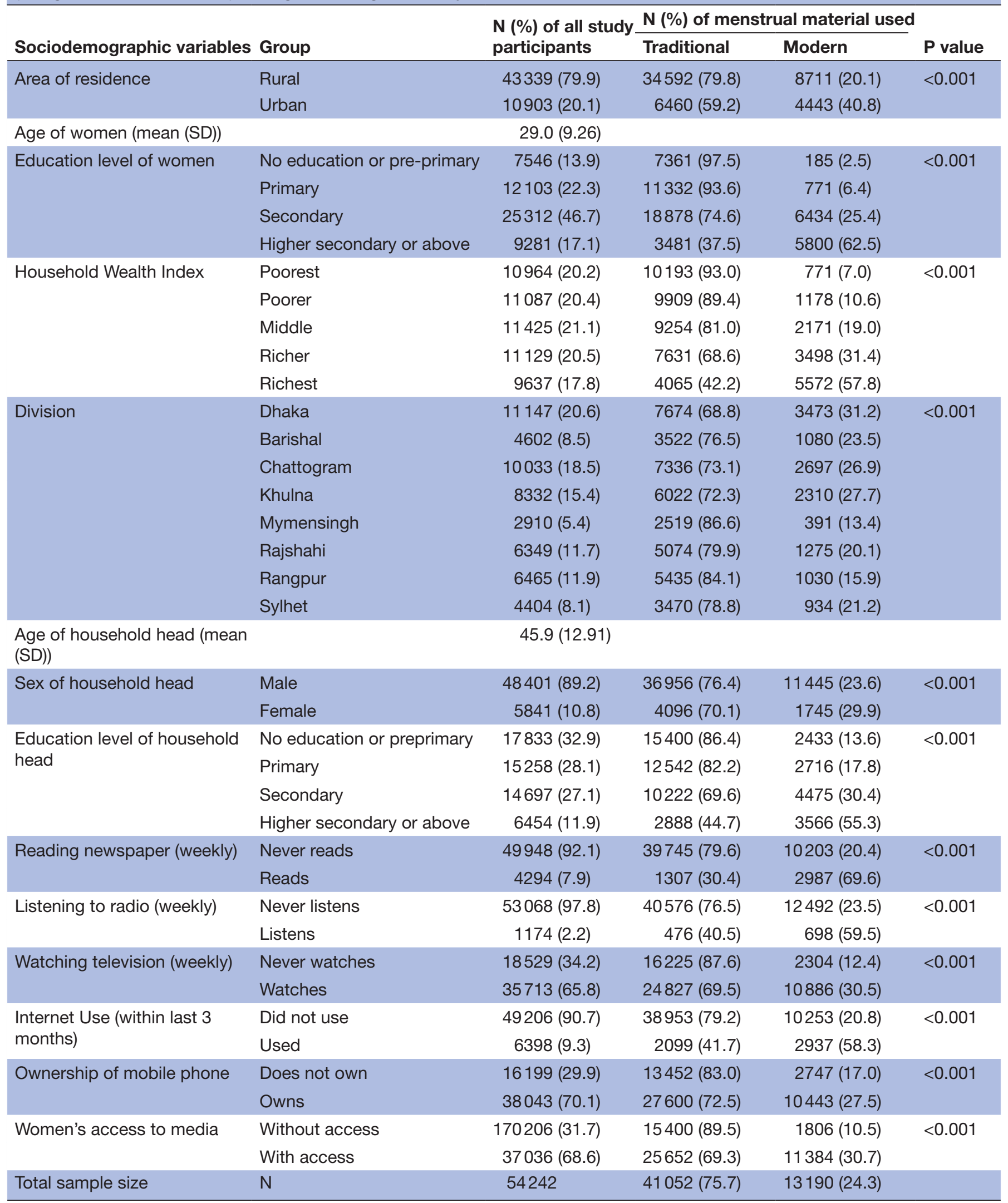

MICS, Multiple Indicator Cluster Survey. 
Table 2 Generalised linear model fitted to binary outcome variable type of material used (traditional, modern) with sociodemographic variables adjusting for cluster and stratawise variations and survey weights

\begin{tabular}{|c|c|c|}
\hline \multirow{2}{*}{$\begin{array}{l}\text { Sociodemographic } \\
\text { variables }\end{array}$} & \multicolumn{2}{|c|}{ Menstrual material used } \\
\hline & AOR $(95 \% \mathrm{Cl})$ & $P$ value \\
\hline Age of women & $0.92(0.91$ to 0.92$)$ & $<0.001$ \\
\hline \multicolumn{3}{|l|}{ Area of residence (ref: rural) } \\
\hline Urban & $1.33(1.21$ to 1.46$)$ & $<0.001$ \\
\hline \multicolumn{3}{|c|}{ Education level of women (ref: no education or pre-primary) } \\
\hline Primary & 1.34 (1.10 to 1.64$)$ & 0.003 \\
\hline Secondary & 3.19 (2.65 to 3.83$)$ & $<0.001$ \\
\hline $\begin{array}{l}\text { Higher secondary or } \\
\text { above }\end{array}$ & $8.58(7.03$ to 10.48$)$ & $<0.001$ \\
\hline \multicolumn{3}{|c|}{ Household Wealth Index (ref: poorest) } \\
\hline Poorer & 1.14 (1.00 to 1.30$)$ & 0.050 \\
\hline Middle & 1.79 (1.57 to 2.04$)$ & $<0.001$ \\
\hline Richer & 2.77 (2.42 to 3.16$)$ & $<0.001$ \\
\hline Richest & 6.92 (5.96 to 8.04$)$ & $<0.001$ \\
\hline \multicolumn{3}{|l|}{ Division (ref: Dhaka) } \\
\hline Barishal & 1.17 (1.03 to 1.33$)$ & 0.018 \\
\hline Chattogram & 0.64 (0.57 to 0.71$)$ & $<0.001$ \\
\hline Khulna & $1.12(1.01$ to 1.25$)$ & 0.039 \\
\hline Mymensingh & 0.52 (0.43 to 0.63$)$ & $<0.001$ \\
\hline Rajshahi & 0.78 (0.69 to 0.87$)$ & $<0.001$ \\
\hline Rangpur & 0.71 (0.62 to 0.81$)$ & $<0.001$ \\
\hline Sylhet & 0.59 (0.49 to 0.72$)$ & $<0.001$ \\
\hline Age of household head & 1.01 (1.01 to 1.02$)$ & $<0.001$ \\
\hline \multicolumn{3}{|c|}{ Sex of household head (ref: male) } \\
\hline Female & $1.27(1.15$ to 1.40$)$ & $<0.001$ \\
\hline
\end{tabular}

Education level of household head (ref: no education or preprimary)

\begin{tabular}{|c|c|c|}
\hline Primary & 1.21 (1.11 to 1.33$)$ & $<0.001$ \\
\hline Secondary & 1.69 (1.54 to 1.85$)$ & $<0.001$ \\
\hline $\begin{array}{l}\text { Higher secondary or } \\
\text { above }\end{array}$ & $2.80(2.49$ to 3.15$)$ & $<0.001$ \\
\hline \multicolumn{3}{|c|}{ Mobile phone ownership (ref: does not own) } \\
\hline Owns & $1.43(1.33$ to 1.54$)$ & $<0.001$ \\
\hline \multicolumn{3}{|c|}{ Women's access to media (ref: without access) } \\
\hline With access & $1.47(1.35$ to 1.60$)$ & $<0.001$ \\
\hline
\end{tabular}

AOR, Adjusted Odds Ratio; Cl, Confidence Interval.

education were more likely to use modern menstrual methods for their MHM, as hypothesised in the theoretical section, as higher odds of using modern menstrual absorbents was associated with access to media and higher education levels. Besides, the sociodemographic variables, such as women's age, area of residence, division, financial condition of household, house heads' age, sex and education level were associated with women's MHM, particularly the use of sanitary napkins during menstruation. A broader understanding of these associations could help in devising and employing intervention strategies regarding MHM in Bangladesh.

Information regarding menstruation and associated hygiene management is not always aptly or timely imparted. ${ }^{36}$ This often makes girls start their menstrual life resorting to unhygienic and unsafe practices, which is likely to be continued a lifetime. Inaccurate information leads to severe misconceptions about menstruation. This is evident from multiple studies in LMICs such as Nepal, India, and Uganda, where a large portion of females consider menstruation to be a curse or illness, or a consequence due to sinful deeds. ${ }^{37-40}$ In line with these studies, the current study found that women's access to media was associated with higher odds of using modern methods/ absorbents for MHM, which could strengthen the argument that the likelihood of using modern methods of MHM would increase with the dissemination of relevant information regarding proper MHM through the media.

The urgent need for appropriate information about MHM is apparent in Bangladesh. There exist several traditional beliefs regarding MHM, such as menstruation being a sign of marriage, or girls needing to refrain from taking nutritious food during the periods. ${ }^{41}$ In the rural context, girls are not allowed to consult with qualified doctors and are expected to be treated by traditional healers or uncertified health workers. ${ }^{41}$ Breaking this traditional mindset requires a continuous flow of correct information, which could be sourced through media such as newspaper, television, radio and internet. ${ }^{42}$ These could be done better through mass media than door-todoor campaigns in a density populated country such as Bangladesh. ${ }^{43}$

Women in slum areas who had poor knowledge regarding MHM and used clothes or rags during menstruation reported several diseases associated with their reproductive organs. ${ }^{17}$ The use of cloths as well as the unhygienic sterilisation before reuse ultimately increased the risk of contracting urogenital diseases. ${ }^{11}$ All these indicate that inadequate access to appropriate knowledge regarding menstruation resulted in unsafe practices of MHM, which corroborated with the findings from the model.

The ownership of mobile phones, another possible indicator of women's awareness, ${ }^{44}$ was also significantly associated with modern material usage of MHM. This further strengthens the argument that access to information is a vital tool in addressing awareness. Access to mobile phones allows the sharing of MHM guidance among peers. Studies have shown that many public health intervention programmes have successfully used mobile phone messaging services to disseminate information leading to increased healthcare access. ${ }^{45} 46$

There is an expectation that higher levels of education are associated with greater awareness regarding MHM, which will result in better hygiene practices during menstruation. A study in India linked the lack of 
knowledge, misconceptions and unsafe material usage to an increase in the risk of reproductive and sexual health-related diseases in adolescent girls. ${ }^{4} \mathrm{~A}$ communitybased health education intervention in India resulted in increased awareness about menstruation and adequate MHM. ${ }^{47}$ However, evidence from multiple studies suggests that formal education about reproductive health is very limited in South Asia. ${ }^{48}$ The sixth-grade home-economics textbook in Bangladesh includes some discussion on MHM, which might not be adequate to confront ageold cultural norms. Therefore, part of the effort to raise awareness regarding MHM should prioritise including substantial information on MHM through texts to women from an early age.

Affordability in accessing healthcare services and products is an important dimension in healthcare access theory. ${ }^{21}{ }^{23}$ Women from poorer households are less likely to purchase costly sanitary napkins and settle for reusing clothes and rags. ${ }^{172549}$ These vulnerabilities compounded with the females' inadequate access to the media and education in poorer households make them the most vulnerable cohort regarding access to the modern MHM. Multiple population-based studies in LMIC settings in India and Kenya indicate that there exists a strong link between women's education and socioeconomic status in determining the use of the type of material used during menstruation. ${ }^{50} 51$

Spatial characteristics are likely to impact access to healthcare services and products through the dimension of accessibility. ${ }^{21}$ This idea was corroborated by the fact that women living in urban areas have better access to the modern materials of MHM than rural women. Similarity, most divisions had considerably fewer users of modern materials compared to Dhaka as the socioeconomic and awareness factors are presumably worse in those divisions. ${ }^{52}$ Since enormous efforts are required to address these long-standing issues, a favourable and cost-effective way to address the improvement of MHM practices of women in these divisions could be raising awareness through media and associated intervention strategies, which have yielded positive results in past case studies. ${ }^{456}$

In order to address the issues discussed around MHM and protect women and girls from the risks of using unhygienic materials and lack of knowledge regarding menstruation, several intervention programmes could be undertaken. Expanding knowledge regarding MHM is likely to result in improved MHM practices, ${ }^{53}$ which are part of software interventions as mentioned in the theoretical framework. This expansion could be effectively done by deploying social awareness campaigns using access to mass media, such as newspapers, televisions, and the internet. ${ }^{54-56}$ These public health campaigns could prove to be effective in providing information to the underprivileged and vulnerable groups in LMIC countries. ${ }^{54} 57$

Drawing inspiration from previously successful campaigns in Bangladesh, ${ }^{56} 5859$ a nationwide awareness campaign addressing MHM could be developed and deployed effectively using mass media. Such software intervention could relay a focused message to a wider audience. This would allow the opportunity to direct the same communication in various forms repeatedly, using television or entertainment programmes to induce awareness, as well as paving the way to introduce community interventions. ${ }^{54} 6061$

While access to different types of media depends on affordability, ${ }^{62}$ several studies have shown that media would be a generic awareness tool for health promotion. ${ }^{62}{ }^{63}$ For example, recent studies in Bangladesh has shown that women who have had access to media were more likely to use health services as these campaigns informed them about health benefits, which could work alongside the peer-to-peer contacts. ${ }^{64}$ Moreover, media campaigns are more cost-effective and no less efficient than door-to-door campaigns, which is more feasible in a densely populated country such as Bangladesh. $^{43}$

In case of MHM awareness, software interventions could be done through text messages regularly on mobile phones, televised programmes designed to raise awareness, radio programmes to discuss about MHM practices and newspaper columns, applications for mobile phones for those with access to the internet, and infographics to impart information regarding the necessities of MHM. For example, 'Meena cartoon', a successful television programme on public health in Bangladesh, delivered messages on gender equity and addressed various social development issues. ${ }^{66}$ More recently, a school-based educational intervention on MHM among young girls in Bangladesh also yielded encouraging results. ${ }^{15}$ Therefore, intervention programmes using the media platforms could offer new avenues to increase access to appropriate MHM.

The study had a few limitations. First, most of the literature consisted of findings pertaining to adolescent girls. The MHM intervention programmes mostly addressed school-going girls as well, which limited the current study to draw literature gaps from them. Second, this is a cross-sectional study, thus no causal inference could be made from the results. However, the findings indicated future possible intervention strategies. Third, this study was limited to quantitative data. Qualitative information might assist in designing interventions in the future. Fourthly, while the survey collected data on whether women had access to media, it did not detail the content of the programmes women follow in these media. Future studies with more targeted data collection could be more specific in evaluating the level of awareness the respondents show regarding the public health campaigns in media and assess the mobile phone contents for more understanding of the direct impact of media and mobile phone uses. Fifth, the models were limited by a few unmeasured confounders which were not available in the survey data. Finally, the extent to which the cloths used by women were cleaned and reused could not be ascertained from the available data. 


\section{Conclusion}

To assess the MHM scenario in Bangladesh, this study utilized the MICS 2019 data to evaluate the spatial distribution of modern menstrual materials used by women and girls of reproductive age in Bangladesh. The role of media and access of mobile phones in MHM for women of reproductive age was further analysed. The results showed that women who frequent media and own mobile phones were less likely to use traditional menstrual methods, which suggests that awareness could play a role in addressing the issue of MHM in Bangladesh.

Software interventions through media, be that newspaper, television, radio, internet, or mobile phone, could be an affordable strategy for LMICs such as Bangladesh. Public health campaigns are part of health policy agendas in Bangladesh; however, a national-level initiative through both public and NGO regarding menstrual management might prove worthwhile, especially given Bangladesh signed to achieve SDGs by 2030.

\section{Twitter Raaj Kishore Biswas @BiswasRaaj}

Acknowledgements The authors would like to acknowledge the United Nations Children's Fund (UNICEF) and Bangladesh Bureau of Statistics, who conducted the nationwide survey and made their data freely accessible.

Contributors AA conceptualised the study, compiled the data, performed statistical analyses and drafted the manuscript. RKB synthesised the analysis plan and finalised the statistical methods as well as edited the manuscript. All authors read and approved the final manuscript.

Funding The authors have not declared a specific grant for this research from any funding agency in the public, commercial or not-for-profit sectors.

Map disclaimer The depiction of boundaries on the map(s) in this article does not imply the expression of any opinion whatsoever on the part of BMJ (or any member of its group) concerning the legal status of any country, territory, jurisdiction or area or of its authorities. The map(s) are provided without any warranty of any kind, either express or implied.

Competing interests None declared.

Patient consent for publication Not required.

Provenance and peer review Not commissioned; externally peer reviewed.

Data availability statement Data are available on reasonable request. This study was based on analysis of a secondary survey data from UNICEF MICS, where all the personal identifiable information of participants had been removed. Informed consent was taken from participants before participating in the survey by the national statistical office, Bangladesh Bureau of Statistics and UNICEF. The data are available online: http://mics.unicef.org/surveys.

Supplemental material This content has been supplied by the author(s). It has not been vetted by BMJ Publishing Group Limited (BMJ) and may not have been peer-reviewed. Any opinions or recommendations discussed are solely those of the author(s) and are not endorsed by BMJ. BMJ disclaims all liability and responsibility arising from any reliance placed on the content. Where the content includes any translated material, BMJ does not warrant the accuracy and reliability of the translations (including but not limited to local regulations, clinical guidelines, terminology, drug names and drug dosages), and is not responsible for any error and/or omissions arising from translation and adaptation or otherwise.

Open access This is an open access article distributed in accordance with the Creative Commons Attribution Non Commercial (CC BY-NC 4.0) license, which permits others to distribute, remix, adapt, build upon this work non-commercially, and license their derivative works on different terms, provided the original work is properly cited, appropriate credit is given, any changes made indicated, and the use is non-commercial. See: http://creativecommons.org/licenses/by-nc/4.0/.

\section{ORCID iDs}

Awan Afiaz http://orcid.org/0000-0001-5801-9087

Raaj Kishore Biswas http://orcid.org/0000-0003-4294-6323
REFERENCES

1 UNICEF. Guidance on menstrual health and hygiene, 2019. Available: https://www.unicef.org/wash/files/UNICEF-Guidance-menstrualhealth-hygiene-2019.pdf

2 Dutta D, Badloe C, Lee H. Supporting the rights of girls and women through menstrual hygiene management (MHM) in the East Asia and Pacific region: realities progress and opportunities 2016.

3 Morison L, Ekpo G, West B, et al. Bacterial vaginosis in relation to menstrual cycle, menstrual protection method, and sexual intercourse in rural Gambian women. Sex Transm Infect 2005;81:242-7.

4 Khanna A, Goyal RS, Bhawsar R. Menstrual practices and reproductive problems: a study of adolescent girls in Rajasthan. $J$ Health Manag 2005;7:91-107.

5 Das P, Baker KK, Dutta A, et al. Menstrual hygiene practices, WASH access and the risk of urogenital infection in women from Odisha, India. PLoS One 2015;10:e0130777.

6 Svare JA, Schmidt H, Hansen BB, et al. Bacterial vaginosis in a cohort of Danish pregnant women: prevalence and relationship with preterm delivery, low birthweight and perinatal infections. BJOG An Int J Obstet Gynaecol 2006;113:1419-25.

7 Hillier SL, Nugent RP, Eschenbach DA, et al. Association between bacterial vaginosis and preterm delivery of a low-birth-weight infant. N Engl J Med 1995;333:1737-42.

8 Hennegan J, Dolan C, Wu M, et al. Measuring the prevalence and impact of poor menstrual hygiene management: a quantitative survey of schoolgirls in rural Uganda. BMJ Open 2016;6:e012596.

9 van Eijk AM, Sivakami M, Thakkar MB, et al. Menstrual hygiene management among adolescent girls in India: a systematic review and meta-analysis. BMJ Open 2016;6:e010290.

10 Tegegne TK, Sisay MM. Menstrual hygiene management and school absenteeism among female adolescent students in Northeast Ethiopia. BMC Public Health 2014;14:1118.

11 Sumpter C, Torondel B. A systematic review of the health and social effects of menstrual hygiene management. PLoS One 2013;8:e62004.

12 Sommer M, Kjellén M, Pensulo C. Girls' and women's unmet needs for menstrual hygiene management (MHM): the interactions between MHM and sanitation systems in low-income countries. J Water Sanit Hyg Dev 2013;3:283-97.

13 Boakye-Yiadom A, Aladago DA, Beweleyir J, et al. Assessing the knowledge, attitude and practice of menstrual hygiene management among junior high schools adolescent females in the Yendi Municipality in the Northern region of Ghana. ESJ 2018;14:467.

14 Alam M-U, Luby SP, Halder AK, et al. Menstrual hygiene management among Bangladeshi adolescent schoolgirls and risk factors affecting school absence: results from a cross-sectional survey. BMJ Open 2017;7:e015508.

15 Haque SE, Rahman M, Itsuko K, et al. The effect of a school-based educational intervention on menstrual health: an intervention study among adolescent girls in Bangladesh. BMJ Open 2014;4:e004607.

16 Muhit IB, Chowdhury ST. Menstrual hygiene condition of adolescent schoolgirls at Chittagong division in Bangladesh. Int J Sci Technol Res 2013;2:58-62.

17 Ahmed R, Yesmin K. Menstrual hygiene: breaking the silence. beyond construction: use by all. A collection of case studies from sanitation and hygiene promotion practitioners in South Asia, 2008.

18 Hennegan J, Sol L. Confidence to manage menstruation at home and at school: findings from a cross-sectional survey of schoolgirls in rural Bangladesh. Cult Heal Sex 2020;22:146-65.

19 United Nations. Transforming our world: the 2030 agenda for sustainable development. United nations sustainable knowledge platform. Sustain Dev Goals 2015.

20 Levesque J-F, Harris MF, Russell G. Patient-centred access to health care: conceptualising access at the interface of health systems and populations. Int J Equity Health 2013;12:18.

21 Penchansky R, Thomas JW. The concept of access. Med Care 1981;19:127-40.

22 Ricketts TC, Goldsmith LJ. Access in health services research: the battle of the frameworks. Nurs Outlook 2005;53:274-80.

23 Saurman E. Improving access: modifying Penchansky and Thomas's Theory of Access. J Health Serv Res Policy 2016;21:36-9.

24 Yagnik A. Theorizing a model information pathway to mitigate the menstrual taboo. Health Promot Int 2019;34:410-9.

25 Hennegan J, Montgomery P. Do menstrual hygiene management interventions improve education and psychosocial outcomes for women and girls in low and middle income countries? A systematic review. PLoS One 2016;11:e0146985.

26 UNICEF. Strategy for water, sanitation and hygiene 2016-2030 2016. 
27 Bangladesh Bureau of Statistics (BBS) \& UNICEF Bangladesh. Progotir pathey, Bangladesh multiple indicator cluster survey 2019, survey findings report 2019.

28 UNICEF MICS. MICS6 TOOLS. Home - UNICEF MICS, 2019.

29 Agresti A, Kateri M. Lectures on categorical data analysis. International encyclopedia of statistical science. Berlin: Springer, 2011.

30 McCullagh P. Generalized linear models. Routledge, 2018.

31 Natural Earth. Natural earth data, 2020.

32 Becker RA, Wilks AR, Minka TP, et al. Maps: draw geographical maps. R package. R package version 3.3.0 2018.

33 Benjamin DJ, Berger JO, Johannesson M, et al. Redefine statistical significance. Nat Hum Behav 2018;2:6-10.

34 Kutner M, Nachtsheim C, Neter J, et al. Applied statistical linear models. McGraw Hill, 2005.

35 Fox J, Monette G. Generalized collinearity diagnostics. J Am Stat Assoc 1992;87:178-83.

36 Chandra-Mouli V, Patel SV. Mapping the knowledge and understanding of menarche, menstrual hygiene and menstrual health among adolescent girls in low- and middle-income countries. Reprod Health 2017;14:30

37 Boosey R, Prestwich G, Deave T. Menstrual hygiene management amongst schoolgirls in the Rukungiri district of Uganda and the impact on their education: a cross-sectional study. Pan Afr Med $J$ 2014;19:253.

38 Shanbhag Det al. Perceptions regarding menstruation and practices during menstrual cycles among high school going adolescent girls in resource limited settings around Bangalore City, Karnataka, India. Int J Collab Res Intern Med Public Heal 2012;4:1353.

39 Goel MK, Kundan M. Psycho-social behaviour of urban Indian adolescent girls during menstruation. Australas Med J 2011:4:49.

40 Adhikari P, Kadel B, Dhungel S. I, et al. Knowledge and practice regarding menstrual hygiene in rural adolescent girls of Nepal. Kathmandu Univ Med J 2006:5:382-6.

41 Mondal BK, Ali MK, Dewan T, et al. Practices and effects of menstrual hygiene management in rural Bangladesh. in 40th WEDC International Conference 2017:24-8.

42 Yagnik AS. Reframing menstruation in India: metamorphosis of the menstrual taboo with the changing media coverage. Health Care Women Int 2014;35:617-33.

43 Madajewicz Met al. Can information alone change behavior? Response to arsenic contamination of groundwater in Bangladesh. J Dev Econ 2007;85:349.

44 Biswas RK, Sarker EB, Kabir E, et al. Presence of books for children in the households of Bangladesh: a district-wise distribution. Read Writ Q 2020;36:65-79.

45 Islam SMS, Lechner A, Ferrari U, et al. Mobile phone intervention for increasing adherence to treatment for type 2 diabetes in an urban area of Bangladesh: protocol for a randomized controlled trial. BMC Health Serv Res 2014:14:586.

46 Prue CS, Shannon KL, Khyang J, et al. Mobile phones improve case detection and management of malaria in rural Bangladesh. Malar $J$ 2013;12:48.

47 Dongre AR, Deshmukh PR, Garg BS. The effect of communitybased health education intervention on management of menstrual hygiene among rural Indian adolescent girls. World Health Popul 2007;9:48-54.

48 Mahon T, Fernandes M. Menstrual hygiene in South Asia: a neglected issue for WASH (water, sanitation and hygiene) programmes. Gend Dev 2010;18:99-113.
49 Dasgupta A, Sarkar M. Menstrual hygiene: how hygienic is the adolescent girl? Indian J Community Med 2008;33:77.

50 Baker KK, Padhi B, Torondel B, et al. From menarche to menopause: a population-based assessment of water, sanitation, and hygiene risk factors for reproductive tract infection symptoms over life stages in rural girls and women in India. PLOS One 2017;12:e0188234.

51 Phillips-Howard PA, Otieno G, Burmen B, et al. Menstrual needs and associations with sexual and reproductive risks in rural Kenyan females: a cross-sectional behavioral survey linked with HIV prevalence. J Women's Health 2015;24:801-11.

52 Dewan AM, Corner RJ. Dhaka megacity: geospatial perspectives on urbanisation, environment and health. Dhaka Megacity: Geospatial perspectives on urbanisation, environment and health. Springer Science \& Business Media, 2014.

53 House S, Mahon T, Cavill S. Menstrual hygiene matters: a resource for improving menstrual hygiene around the world. Reprod Health Matters 2012;21:257-9.

54 Wakefield MA, Loken B, Hornik RC. Use of mass media campaigns to change health behaviour. Lancet 2010;376:1261-71.

55 Lecouturier J, Rodgers $\mathrm{H}$, Murtagh MJ, et al. Systematic review of mass media interventions designed to improve public recognition of stroke symptoms, emergency response and early treatment. BMC Public Health 2010;10:784.

56 Rahman MS, Rahman ML. Media and education play a tremendous role in mounting AIDS awareness among married couples in Bangladesh. AIDS Res Ther 2007;4:10.

57 Cecchini M, Sassi F, Lauer JA, et al. Tackling of unhealthy diets, physical inactivity, and obesity: health effects and cost-effectiveness. Lancet 2010;376:1775-84.

58 Sanghvi T, Haque R, Roy S, et al. Achieving behaviour change at scale: Alive \& Thrive's infant and young child feeding programme in Bangladesh. Matern Child Nutr 2016;12:141-54.

59 Do MP, Kincaid DL. Impact of an entertainment-education television drama on health knowledge and behavior in Bangladesh: an application of propensity score matching. $J$ Health Commun 2006;11:301-25.

60 Boles M, Adams A, Gredler A, et al. Ability of a mass media campaign to influence knowledge, attitudes, and behaviors about sugary drinks and obesity. Prev Med 2014;67:S40-5.

61 Sharma SK, Sawangdee Y, Sirirassamee B. Access to health: women's status and utilization of maternal health services in Nepal. $J$ Biosoc Sci 2007;39:671-92.

62 Hadi A. Promoting health knowledge through micro-credit programmes: experience of brac in Bangladesh. Health Promot Int 2001;16:219-27.

63 Hasan S, Baten A. Role of mass media in promotion of family planning in Bangladesh. J App/ Sci 2005;5:1158-62.

64 Biswas RK, Rahman N, Islam H, et al. Exposure of mobile phones and mass media in maternal health services use in developing nations: evidence from urban health survey 2013 of Bangladesh. Contemp South Asia 2020;9:1-14.

65 Chowdhury AR, Cash RA. A simple solution: teaching millions to treat diarrhoea at home. Dhaka University Press, 1996.

66 McKee N, Aghi MB, Carnegie R, et al. Cartoons and comic books for changing social norms: Meena, the South Asian girl. in Entertainment-Education and social change. His Res Pract 2004:331-49. 